\title{
DE ARISTÓTELES A HEIDEGGER UN RECORRIDO DEL LUGAR A LA ESPACIALIDAD DEL DASEIN
}

\section{FROM ARISTOTLE TO HEIDEGGER A TOUR OF THE PLACE TO THE SPATIALITY OF DASEIN}

Carlos Quenaya Mendoza*

\begin{abstract}
RESUMEN
El presente artículo ensaya una lectura de las nociones de lugar en Aristóteles y espacialidad del Dasein en Heidegger, concentrándose en el Libro IV de la Física y en los parágrafos 22, 23 y 24 del capítulo tercero de la primera parte de Ser y Tiempo. Asimismo se hace referencia a sus particulares concepciones metafísicas, y se intenta destacar algunas significativas relaciones sin perder de vista el horizonte filosófico que distingue a ambos pensadores.
\end{abstract}

\section{PALABRAS CLAVE:}

Dasein, metafísica, physis, ontología, hermenéutica, fenomenología, mundanidad.

\begin{abstract}
This article is an essay of reading Aristotle's notions of place, and spatiality of Dasein in Heidegger, focusing in Book IV of Physics and in paragraphs 22, 23 and 24 of chapter three of the first part of Being and Time. In addition, a reference to their particular metaphysical conceptions is made, and some significant relationships are tried to be highlighted without losing sight of the philosophical horizon that distinguishes both thinkers.
\end{abstract}

\section{KEY WORDS:}

Dasein, metaphysics, physis, ontology, hermeneutics, Phenomenology, worldliness.

* Docente de la Universidad Femenina del Sagrado Corazón: cquenaya@unife.edu.pe 


\section{INTRODUCCIÓN}

El pascaliano temor a los espacios infinitos es signo del desplazamiento moderno del lugar central, fijo e inmóvil que el ser humano había reservado para sí dentro del orden universal. Las concepciones aristotélica y tolemaica serán enérgicamente refutadas por la astronomía y la física de Galileo y Newton. Intentar establecer correspondencias entre Aristóteles y Heidegger supone, entonces, dibujar un arco que comienza en el siglo IV a.C. y alcanza todavía la actualidad, sin olvidar la discusión moderna y el nuevo lenguaje que heredamos de ella.

Existen, entre el filósofo griego y el alemán, conexiones importantes que pueden rastrearse ensayando diferentes aproximaciones a sus obras. Nuestro propósito es desarrollar algunas correspondencias presentes en la idea de lugar en Aristóteles y la espacialidad del Dasein en Heidegger, enfocándonos en el Libro IV de la Física y en los parágrafos 22, 23 y 24 del capítulo tercero de la primera parte de Ser y Tiempo.

¿Cuáles son los vínculos entre Física y Ser y Tiempo? Enmarcaremos nuestra exposición dentro del ámbito ontológico que estos libros comparten, aunque desde supuestos y búsquedas muy diferentes. Asimismo, haremos algunas precisiones terminológicas para comprender, dentro de su propio contexto, los conceptos de Aristóteles, sin dejar de lado su visión del mundo y la influencia que tuvo en los siglos posteriores.

\section{La ontología de Física y Ser y Tiempo}

¿Qué clase de libro es la Física aristotélica?, ¿qué significó la phýsis para los griegos?, ¿cómo interpretó esta noción Aristóteles? El filósofo italiano Giovanni Reale, intentando esclarecer estas cuestiones, dirá: "En opinión de Aristóteles, la segunda ciencia teorética es la 'física' o 'filosofía segunda', que tiene como objeto la investigación de la realidad sensible, que se caracteriza intrínsecamente por el movimiento, así como la metafísica tiene por objeto la realidad suprasensible, caracterizada intrínsecamente por la ausencia absoluta de movimiento". (1992: 69).

Así, frente a la filosofía primera (metafísica) la física se definiría como una suerte de filosofía segunda, en tanto que su objeto de investigación sería la realidad sensible en movimiento. Esto, como veremos, precisa de algunas matizaciones. ¿Son la física y la metafísica dos disciplinas opuestas y claramente discernibles entre sí? En palabras de Aristóteles: "En efecto, la física estudia los accidentes y los principios de las cosas que son, en tanto que son movidas, y no en tanto que cosas que son (mientras que hemos dicho que la ciencia primera se ocupa de éstas, en la medida en que las cosas que estudia son cosas que son, y no en tanto que son alguna otra cosa)". (1994: 1061b 30).

A simple vista se constata la distinción entre física y metafísica, sólo que, en el párrafo citado, no se realiza una separación explícita de la realidad sensible de la suprasensible. Se dice que la física estudia las cosas que son, en tanto que son movidas. En cambio, la metafísica estudiaría las cosas que son en tanto que son, en un sentido más radical. Aquí, por lo menos, podríamos inferir que la física es una especie de metafísica focalizada en las cosas desde la perspectiva del movimiento. En el ensayo introductorio a su traducción de la Física, Guillermo R. de Echeandía sostiene que "el objeto de la física es 
el movimiento de las cosas desde el punto de vista de su phýsis, esto es, de su ser, de su substancia. Esto significa que, en rigor de los términos, la física de Aristóteles es una ontología del movimiento". (Aristóteles 1998: 39)

No habría, pues, una oposición binaria entre las dos disciplinas. Más adelante, de manera más enfática agregará que "... lo que nos muestra una lectura atenta de la Metafísica es más bien que el problema del ser se halla íntimamente entrelazado con el problema del movimiento, hasta el punto de que se puede afirmar que la física impregna toda la reflexión ontológica de Aristóteles". (Aristóteles 1998: 40). Esta lectura nos parece mucho más sugerente, pues relaciona de manera más dinámica las indagaciones de Aristóteles. Entender la física como una ontología del movimiento nos ayudará también a trazar un puente con Ser y Tiempo, libro que de modo mucho más explícito se presenta como una investigación ontológica, aunque con características que, por supuesto, son el resultado de un diálogo con la tradición filosófica antigua y moderna, por decirlo de manera escueta.

Pero, ¿qué fue, entonces, la phýsis para los griegos? Según Guillermo R. de Echeandía: "Para los jonios, la física era la filosofía, pues phýsis era el nombre para todo lo real, para la totalidad del ente. La pregunta por la phýsistoónton sería entonces para ellos la pregunta auténticamente radical. (Aristóteles 1998: 31). Preguntarse por la phýsis suponía interrogarse por la totalidad del ente. La phýsis no se reducía aquí a la naturaleza sensible. En la misma línea de interpretación Heidegger escribirá:

Al ente como tal y en su totalidad, los griegos lo llamaron ýंбıs. Pero debemos aludir al hecho de que ya dentro de la filosofía griega se introdujo rápidamente un estrechamiento de la palabra, sin que desapareciera de tal filosofía aquella significación originaria, tomada de la experiencia, del saber y de la actividad que caracterizan. Todavía en Aristóteles, cuando habla de los fundamentos del ente como tal (Cfr. Met. I, 1003 a 27), resuena el conocimiento de ese significado primigenio. (1956: 52)

En otras palabras, tendríamos que establecer un primer momento donde el término phýsis abarcaría la totalidad del ente y que paulatinamente iría reduciendo su horizonte de significado, pero sin perder completamente su vigencia en Aristóteles. En ese sentido, el físico y el filósofo se identificarían plenamente. Así podemos entender la afirmación de Heidegger, según la cual: "La 'Física' determina desde el comienzo la esencia y la historia de la Metafísica". (1956: 53)

En Ser y Tiempo, Heidegger se propone volver a plantear la pregunta por el ser. Esta pregunta que, para Heidegger, es la pregunta fundamental, debe formularse analizando, en primer lugar, al ente que pregunta: el Dasein. La ontología heideggeriana, así, se vuelve hermenéutica, pues la manera de abordar al Dasein se realizará mediante la interpretación de la vida cotidiana. Este análisis que en Ser y Tiempo se conoce como analítica existencial o analítica del Dasein, tuvo como antecedente próximo un trabajo que Heidegger redactó para ocupar una plaza como profesor extraordinario en la Universidad de Marburgo. No es casual que sus Interpretaciones fenomenológicas sobre Aristóteles (Indicación de la situación hermenéutica), sean el antecedente inmediato de la obra más famosa de este filósofo. 
Heidegger leerá a Aristóteles para llevar a cabo lo que llama hermenéutica de la facticidad. A través de su crítica y sirviéndose, por ejemplo, del concepto de phrónesis, Heidegger ensayará una interpretación de la vida práctica que ponga sobre un nueva perspectiva las interpretaciones que sobre el ser humano y el mundo han ido proponiendo las diferentes filosofías en Occidente.

El interés de Heidegger se encuentra en devolver la reflexión filosófica a la vida práctica, intentando vislumbrar la comprensión que ya tenemos en nuestro acaecer cotidiano, sin imponer estructuras conceptuales que simplifiquen nuestra manera de ser en el mundo. Por eso nos llama particularmente la atención cuando Jonathan Lear, a propósito de Aristóteles, escribe:

Está convencido de que la verdad ha de armonizar con la realidad que percibimos patentemente en torno a nosotros. La función de la filosofía es no minar nuestras creencias preteóricas, sino ayudarnos a conferirles sentido. La filosofía nos da una idea más profunda de por qué nuestras creencias comunes son verdaderas. Nuestras creencias comunes acerca del mundo se convierten, pues, en un punto de partida para la actividad filosófica que se puede modificar mas nunca abandonar por completo. Es, pues, un axioma de su método filosófico que un argumento que lleva a una conclusión que choca con nuestras creencias comunes acerca del mundo, por coercitivo que sea, ha de contener algún fallo. (1994: 75)

Este párrafo que Lear dedica a Aristóteles podría suscribirse prácticamente sin alteraciones para referirnos al proyecto del joven Heidegger. Tal es el marco de ideas desde el cual podemos comenzar a vislumbrar algunas de las conexiones entre las ideas sobre el lugar en Aristóteles y la espacialidad del Dasein en Heidegger.

\section{El tópos aristotélico como lugar}

La traducción más adecuada para la palabra "tópos" es la de "lugar". El "tópos" griego se convertiría con el tiempo en "locus" o "spatium", que en latín tuvo el sentido de campo de carreras o de batalla. Estos vocablos se traducirían, más tarde, por "espacio", que en la física moderna se usaría como una noción geométrica mucho más abstracta que la de lugar. Para Aristóteles el lugar no es el espacio, pues no concebirá la posibilidad de un lugar sin objetos, o de un lugar vacío. Tal vez el término "kenón" sería el equivalente aristotélico más cercano al espacio moderno, pero el estagirita argumentará en contra de la existencia del "kenón" o vacío.

Sambursky, plenamente consciente de estas precisiones, afirmará:

Desde Newton los físicos se han formado en el hábito de considerar el espacio como una estructura geométrica desplegada en el vacío que liga entre sí los puntos geométricos en el sobreimpresionados. Aristóteles rechazó cualquier descripción física realizada a partir de una geometría abstracta que se extendiera más allá de los límites de la materia o en los vacíos entre sus partes. En su lugar identificó el espacio con el volumen ocupado por la materia, una identificación que requería la continuidad de aquélla. Es característica de esta concepción el que Aristóteles no hiciera uso de la palabra "espacio", sino de la palabra "lugar", para expresar la localización de un cuerpo dado. "Lugar" es un término mucho más concreto que "espacio", proporciona una definición geométrica de un cuerpo concreto en 
términos de los límites entre éste y su entorno material, es decir, entre éste y el cuerpo o cuerpos que están en contacto directo con toda su periferia.

La combinación aristotélica de geometría y materia para formar su concepto de lugar no es disimilar a la concepción del espacio en la Teoría General de la Relatividad. También ésta rechaza el retrato newtoniano del espacio como una especie de "caja" infinita en que se mueven los cuerpos físicos. En lugar de ello representa el espacio como un tipo de comunión del cuerpo y sus contornos: es el cuerpo el que determina la geometría de su entorno y ésta no puede ser artificialmente separada del cuerpo mismo. (1990: 121)

Aunque sugerente, no es este el lugar para explorar el vínculo entre la concepción de espacio de la Teoría de la Relatividad y la de tópos en Aristóteles. El tópos aristotélico es un concepto relacional, que hace referencia a la pluralidad de lugares concretos, y debe, por tanto, distinguirse del concepto de espacio moderno, que, para usar la imagen de Sambursky, concibió al espacio como una especie de caja infinita donde se moverían los cuerpos físicos.

¿Cuál es, entonces, el vínculo de la noción de lugar y la espacialidad del Dasein?

\section{Análisis de la noción de lugar en Aristóteles y la espacialidad del Dasein en Heidegger}

La física aristotélica es, de acuerdo a nuestro examen, una ontología del movimiento. La pregunta por el lugar se inscribe dentro de su investigación de la phýsis, que si bien puede entenderse como naturaleza, también arrastra consigo el pasado de una tradición que incluía en este concepto la totalidad del ente.

Heidegger, por otro lado, propone explícitamente replantear la pregunta por el ser. Su proyecto consiste en profundizar, desde una nueva mirada, en la necesidad de esta pregunta. Para poder hacerlo piensa que es fundamental analizar al ente que pregunta (el Dasein). Dentro de este esquema de investigación realizará el análisis de la espacialidad del Dasein.

De lo anterior se desprende que las indagaciones sobre el lugar y la espacialidad en Aristóteles y Heidegger comparten una dirección ontológica. La diferencia más importante estriba en que para Aristóteles la pregunta por el lugar tiene como objetivo la elucidación del problema del movimiento (del ente sensible que se mueve). En cambio, Heidegger se preguntará por la espacialidad con el fin de aclarar la estructura del Dasein.

Para Heidegger el ser humano está en el mundo de un modo esencialmente diferente al de los demás entes. Un ser humano no está en el mundo de la misma manera en que, por ejemplo, el agua está dentro del vaso. No se trata de que el ser humano simplemente esté "dentro de" u ocupe un espacio. Heidegger va a intentar averiguar la espacialidad propia del Dasein. El filósofo griego, por otra parte, no hará esta distinción. Podríamos inferir que, en tanto Aristóteles realiza una diferenciación nítida entre los cuerpos y el lugar (pues es imposible que el lugar sea un cuerpo, porque entonces habría dos cuerpos en el mismo lugar), el ser humano sería un cuerpo más entre los muchos que ocupan los distintos lugares.

En un sentido semejante podemos analizar la idea de "lugar propio" que 
Aristóteles y Heidegger proponen. Para el estagirita:

...cada uno de estos cuerpos (los cuerpos naturales simples: fuego, tierra y semejantes), si nada lo impide, es llevado hacia su lugar propio, unos hacia arriba y otros hacia abajo. Estas son las partes o especies del lugar, el arriba, el abajo y el resto de las seis direcciones. Ahora bien, estas direcciones (arriba y abajo, derecha e izquierda, etc.) no sólo son tales con respecto a nosotros, ya que para nosotros una cosa no siempre está en la misma dirección, sino que cambia según cambie nuestra posición, pudiendo una misma cosa estar así a la derecha y a la izquierda, arriba y abajo, delante y detrás. Pero en la naturaleza cada una es distinta, independientemente de nuestra posición, pues el "arriba" no es una dirección casual, sino adonde son llevados el fuego y los cuerpos ligeros, y de la misma manera el "abajo" tampoco es una dirección casual, sino adonde son llevados los cuerpos pesados y terrestres, de manera que ambas direcciones difieren no sólo con respecto a la posición, sino también por un cierto poder. (1998: 208b 10-20)

Aquí vale la pena hacer una confrontación más o menos detenida con Heidegger. A pesar de que Aristóteles admita la relatividad de las seis direcciones (con respecto a nosotros), anota que ello no se cumple con respecto a la naturaleza, donde sí hay un arriba, un abajo, delante, detrás, izquierda y derecha absolutos. Estas direcciones en la naturaleza son referentes absolutos, porque el mundo en la cosmología aristotélica es un todo ordenado. No hay que olvidar que desde su concepción teleológica todo tiene una finalidad. Lo pesado abajo y lo ligero arriba, por ejemplo.
Heidegger, en cambio, se encuentra lejos de este tipo de distinciones y ahondará en la primera consideración: la referencialidad de las direcciones en que se mueve cotidianamente el Dasein:

El lugar propio y la multiplicidad de lugares propios no deben ser interpretados como el "dónde" de un simple estar-ahí de las cosas. El lugar propio es siempre el preciso "ahí" o "aquí" al que un útil pertenece en propiedad (des HingehorenseinesZeugs). La "pertinencia" (Hingehorigkeit) depende siempre del carácter pragmático de lo a la mano, es decir, de su pertenencia respeccional a un todo de útiles. Pero, la pertinencia que hace determinables los lugares propios de un conjunto de útiles tiene como condición de posibilidad el adónde en general, hacia dentro del cual se le asigna a un determinado complejo de útiles la totalidad de lugares propios. Este adónde (Wohin) de la posible pertinencia pragmática que en el trato ocupado se halla de antemano ante la mirada circunspectiva, es lo que nosotros llamamos la zona (Gegend). (1997: 128)

Este pasaje ilustra una concepción relativista del lugar. Los lugares propios, de acuerdo a Heidegger, se encuentran siempre en referencia a la pertenencia a un determinado conjunto de útiles. El lugar propio de, digamos, mis anteojos, se encuentra justamente delante de mis ojos. Ubicarlos en mis espaldas carecería de sentido, pues la pertinencia de un útil se determina por las referencias que hace a otros útiles. Una zona sería, así, una biblioteca donde encontraríamos los diferentes lugares propios adecuados para libros, escritorios, anaqueles, lapiceros, computadoras, etc. Heidegger, obviamente, ya no puede concebir el lugar desde referencialidades absolutas. 


\section{4. ¿Desmundanizar el lugar o mundanizar el espacio?}

Aristóteles define el lugar como el límite del cuerpo continente (Cf. 1998: 212a 5). Su análisis lo lleva a sostener que el lugar sería aquello que envuelve al cuerpo (sin identificarse con su forma), su límite, el cual tiene la capacidad de contener distintos cuerpos, siendo imposible que quedara alguna vez vacío. Esta definición aristotélica que no identifica lugares y cuerpos supone un proceso de racionalización del lugar, producto de la búsqueda de su conceptualización. Aun cuando "tópos" alude a un lugar concreto (no traducible por espacio) se puede advertir en el razonamiento de Aristóteles una fuerza abstractiva que conduciría, en términos heideggerianos, a desmundanizar el lugar. Por contraposición, la tarea de Heidegger radicará precisamente en mundanizar el espacio cotidiano, pues éste no es simplemente una caja infinita donde están superpuestos los cuerpos, sino un conjunto vivo de referencialidades humanas. El lugar en el que cotidianamente nos encontramos está lleno de significado.

El filósofo alemán tratará de probar que la espacialidad del Dasein no es nunca primariamente el espacio de la física, sino el lugar concreto y real en que nos movemos diariamente. Así, pues, podemos entrever algunas de las relaciones entre la espacialidad heideggeriana y el tópos aristotélico, pues éste aspira a recuperar el lugar, el "tópos" como sentido primordial para la vida fáctica. Este contacto de conceptos, sin embargo, es sutil porque el razonamiento aristotélico impulsará la noción de lugar en la dirección de la que justamente quiere retornar Heidegger: allî donde se concibe al lugar como espacio geométrico.

\section{REFERENCIAS:}

\section{ARISTÓTELES}

1994 Metafísica. Madrid: Editorial Gredos.

1998 Física. Madrid: Editorial Gredos.

HEIDEGGER, M.

1956 Introducción a la metafísica. Buenos Aires: Editorial Nova.

1997 Ser y Tiempo. Santiago de Chile: Editorial Universitaria.

2002 Interpretaciones fenomenológicas sobre Aristóteles. Indicación de la situación hermenéutica (Informe Natorp). Madrid: Editorial Trotta.

LEAR, J. (1994) Aristóteles. Madrid: Alianza Editorial.

REALE, G. (1992) Introducción a Aristóteles. Barcelona: Editorial Herder.

SAMBURSKY, S. (1990) El mundo físico de los griegos. Madrid: Alianza Editorial. 